\title{
Semiquantitative reverse transcription-polymerase chain reaction to evaluate the expression patterns of genes involved in the oestrogen pathway
}

\section{J M Rey ${ }^{1,2}$, P Pujol ${ }^{1,2}$, P Callier ${ }^{1}$, V Cavailles ${ }^{2}$, G Freiss $^{2}$, T Maudelonde ${ }^{1,2}$ and J P Brouillet ${ }^{1,2}$}

\footnotetext{
${ }^{1}$ Laboratoire de Biologie Cellulaire et Hormonale, CHU Arnaud de Villeneuve, 371 av. du Doyen G Giraud, 34295 Montpellier Cedex 5, France

${ }^{2}$ Unité Endocrinologie Moléculaire et Cellulaire des Cancers, INSERM U 540, Université de

Montpellier I, 60 rue de Navacelles, 34090 Montpellier, France

(Requests for offprints should be addressed to J P Brouillet, Laboratoire de Biologie Cellulaire et

Hormonale, CHU Arnaud de Villeneuve, 371 av. du Doyen G Giraud, 34295 Montpellier Cedex 5,

France; Email: jp-brouillet@chu-montpellier.fr)
}

\begin{abstract}
The increasing number of factors to be taken into account in the oestrogen transcriptional process has created a need to develop a rapid screening method to evaluate their role in physiology and pathology. Molecular biology techniques enable gene expression studies at the mRNA level with small amounts of tissues. We therefore developed a semiquantitative reverse transcription-polymerase chain reaction (RT-PCR) technique using fluorescent oligonucleotides to analyse simultaneously a large panel of interrelated genes involved in the oestrogen transcriptional pathway using a moderately expressed housekeeping gene, the hypoxanthine
\end{abstract}

phosphoribosyltransferase gene (HPRT), as the reference gene. Expression levels of oestrogen receptors (ER $\alpha, E R \beta)$, cofactors AIB1, RIP140, SMRT and the Fas-associated protein-tyrosine phophatase-1 (FAP-1) genes were evaluated in breast, endometrial and ovarian cancer cell lines and in three ER $\alpha$-positive and three ER $\alpha$-negative breast cancer tumours. This technique provides a rapid and reliable way to quantitate simultaneously numerous mRNAs of genes involved in the oestrogen pathway from small amounts of tissues. Fournal of Molecular Endocrinology (2000) 24, 433-440

\section{INTRODUCTION}

In a wide range of tissues, oestrogens act as transcriptional regulators via their specific receptors, the oestrogen receptors $\alpha(\mathrm{ER} \alpha)$ and $\beta(\mathrm{ER} \beta)$. Recently, numerous factors involved in ER transcriptional regulation as co-activators or co-inhibitors (for review see Horwitz et al. 1996) and in anti-oestrogen sensitivity as protein tyrosine-phosphatases (Freiss et al. 1998) have been documented, but their cellular physiology and pathology roles are still unknown and their medical diagnosis and pronostic potential need to be assessed. The increasing number of parameters to be taken into account in the oestrogen transcriptional process prompted us to develop rapid screening methods. The protein-based methodology, involving protein quantitation with antibody recognition, is not suitable for this use because it is often time consuming, not adapted to small amounts of tissue, and antibodies of newly characterised proteins are not always available. Conversely, the development of molecular biology techniques enables detection of gene expression at the RNA level with small amounts of tissue. Since many of these new factors are interrelated, it is important to analyse them simultaneously in order to identify the most relevant ones. Recently, it has been suggested that some of these cofactors might be involved in gynaecological pathologies: amplified in breast cancer 1 (AIB1) (Anzick et al. 1997, Bautista et al. 1998), receptor interacting protein 140 (RIP140) (Cavaillès et al. 1995), silencing mediator of retinoid and thyroid hormone (SMRT) (Smith et al. 1997) and the Fas-associated protein tyrosinephosphatase-1 (FAP-1) in tamoxifen sensitivity (Freiss et al. 1998). 
TABLE 1. Forward (F) and reverse (R) oligonucleotide sequences for PCR amplification and co-amplification

\begin{tabular}{|c|c|c|c|}
\hline & Oligonucleotides sequences & $\begin{array}{l}\text { First annealing } \\
\text { nucleotide }\end{array}$ & $\begin{array}{l}\text { Size of PCR } \\
\text { products }(\mathrm{bp})\end{array}$ \\
\hline \multicolumn{4}{|l|}{ Oligonucleotides } \\
\hline$\beta 2 \mathrm{~m} \mathrm{R}$ & 5'-TTAAAAAGCAAGCAAGCAGA-3' & 1295 & \\
\hline HPRT F & 5'-TGTAATGACCAGTCAACAGGG-3' & 401 & 213 \\
\hline HPRT R & 5'-TGGCTTATATCCAACACTTCG-3' & 593 & \\
\hline RIP F & 5'-CTGCCATCCAGTTTTGGATC-3' & 3772 & 225 \\
\hline RIP R & 5'-CGCATACAGAAGTGTTAAACAACC-3' & 3973 & \\
\hline SMRT F & 5'-GAAAAGTCCATCCTCACGTC-3' & 2860 & 364 \\
\hline SMRT R & 5'-TCCATGAGGGTAGGGTAGAC-3' & 3204 & \\
\hline FAP1 F & $5^{\prime}$-ACCTTGAAGACTTTGAACTGGA-3' & 5562 & 304 \\
\hline FAP1 R & 5'-AGGCAACATTGGTATTCTGG-3' & 5846 & \\
\hline
\end{tabular}

The aim of this study was to develop a new approach for rapidly evaluating a large panel of genes involved in the oestrogen transcriptional pathway, using a relative semi-quantitative reverse transcription-polymerase chain reaction (RT-PCR) method to define expression patterns. We evaluated the mRNA expression levels of the oestrogen receptors $\mathrm{ER} \alpha$ and $\mathrm{ER} \beta$, and of the steroid receptors cofactors AIB1, RIP140, SMRT and FAP-1 in breast, endometrial and ovarian cancer cell lines and in breast cancer samples.

\section{MATERIALS AND METHODS}

\section{Cell lines and patients}

Human breast (MCF-7, MDA-MB231, ZR75 and T47D), endometrial (Ishikawa) and ovarian (BG1) cancer cells were derived from stocks routinely maintained in our laboratory. Monolayer cultures were grown in Dulbecco's modified Eagle's medium (DMEM) or in Ham's/DMEM (1:1) supplemented with 10\% fetal calf serum (GIBCO BRL, Eraguy, France) and antibiotics. Pellets were obtained after trypsination of $75 \mathrm{~cm}^{2}$ culture flasks followed by $3000 \times \boldsymbol{g}$ centrifugation for $5 \mathrm{~min}$.

Pellets of breast cancer tissues were obtained after high speed centrifugation of cytosol samples routinely used for oestrogen and progesterone (PR) receptors assays. Three ER $\alpha / \mathrm{PR}$-positive (more than $122 \mathrm{fmoles} / \mathrm{mg}$ total protein) and $3 \mathrm{ER} \alpha / \mathrm{PR}$ negative (less than 4 fmoles/mg total protein) breast cancer samples were selected.

\section{RNA preparation}

Total RNAs of cell lines and patient samples were prepared by TRizol extraction (GIBCO BRL,
Eraguy, France). Briefly, the pellets were homogenised in $1 \mathrm{ml}$ TRizol reagent; $0.2 \mathrm{ml}$ chloroform was added and samples were incubated for $5 \mathrm{~min}$ at room temperature. After centrifugation $(12000 \times \boldsymbol{g}$ for $15 \mathrm{~min}$ at $4{ }^{\circ} \mathrm{C}$ ), total RNAs were precipitated from the aqueous upper phase using $500 \mu \mathrm{l}$ isopropanol and then resuspended in $50 \mu \mathrm{l}$ RNasefree water and stored at $-80{ }^{\circ} \mathrm{C}$. Extracted amounts of RNA were determined by measuring absorbance at $260 \mathrm{~nm}$.

\section{Reverse transcription}

cDNA synthesis was performed in $50 \mathrm{mM}$ Tris$\mathrm{HCl}\left(\mathrm{pH} \mathrm{8.3)}, 75 \mathrm{mM} \mathrm{KCl}, 3 \mathrm{mM} \mathrm{MgCl}_{2}, 10 \mathrm{mM}\right.$ dithiothreitol, $300 \mu \mathrm{M} \mathrm{dNTP}$ and $2.72 \mathrm{mM}$ random primers (Promega, Lyon, France) with $2 \mu \mathrm{g}$ total RNA in a final volume of $46 \mu$ l. Samples were heated at $65{ }^{\circ} \mathrm{C}$ for $10 \mathrm{~min}$ and rapidly chilled on ice before adding 80 units RNase inhibitor (Promega) and 400 units M-MTV reverse transcriptase (GIBCO BRL). The final mixture was incubated at $37^{\circ} \mathrm{C}$ for $60 \mathrm{~min}$ and then heated at $95^{\circ} \mathrm{C}$ for $5 \mathrm{~min}$.

\section{PCR}

\section{PCR and oligonucleotides}

PCR amplifications and co-amplifications were performed in $20 \mathrm{mM}$ Tris- $\mathrm{HCl}(\mathrm{pH} 8.55), 16 \mathrm{mM}$ $\left(\mathrm{NH}_{4}\right)_{2} \mathrm{SO}_{4}, 2.5 \mathrm{mM} \mathrm{MgCl}_{2}, 50 \mu \mathrm{M}$ dNTP mix, and $200 \mathrm{nM}$ of each forward and reverse oligonucleotide, along with 0.325 units Taq DNA polymerase (Bioprobe, Montreuil, France) and $1 \cdot 25 \mu \mathrm{l} \mathrm{cDNA}$ mixture in a final volume of $12 \cdot 5 \mu \mathrm{l}$. After an initial denaturation step, PCRs were carried out under the following conditions: $30 \mathrm{~s}$ denaturing at $95{ }^{\circ} \mathrm{C}, 50 \mathrm{~s}$ annealing at $52^{\circ} \mathrm{C}$ (cofactors and FAP-1) or $60^{\circ} \mathrm{C}(\mathrm{ER} \alpha / \mathrm{ER} \beta)$, and 
1 min extension at $72^{\circ} \mathrm{C}$ (Table 1 ) on a DNA Thermo Cycler (Perkin Elmer, Courtaboeuf, France). Oligonucleotides were designed according to the cDNA organisation of $\beta-2$ microglobulin ( $\beta 2 \mathrm{~m}$ ) (Suggs et al. 1981), hypoxanthine phosphoribosyltransferase (HPRT) (Jolly et al. 1983), RIP140 (Cavaillès et al. 1995), AIB1 (Anzick et al. 1997), SMRT (Chen \& Evans 1995), and FAP-1 (Maekawa et al. 1994) to homogenise the annealing temperatures (Table 1). $\mathrm{ER} \alpha / \mathrm{ER} \beta$ competitive RT-PCRs were assessed using published oligonucleotides (Pujol et al. 1998). Amplification products were run on a $2 \%$ agarose gel or on a $5 \%$ acrylamide gel and stained with ethidium bromide. Two microlitres $1 / 10 \mathrm{PCR}$ dilutions were added to $20 \mu$ deionized formamide $/ 0 \cdot 7 \mu \mathrm{l} \mathrm{GS400HD}$ (Perkin Elmer). Samples were heated for $1 \mathrm{~min}$ at $95{ }^{\circ} \mathrm{C}$ and rapidly chilled on ice before loading onto an Applied Biosystems 310A apparatus (Perkin Elmer), according to the manufacturer's instructions. Peak height values were determined and co-amplification results were expressed in percentages of the housekeeping gene used as internal control. Expression levels were determined on the basis of two independent sets of RT-PCR obtained from two independent cell cultures.

\section{Reverse transcription standardisation using the reference gene}

As the yields of the reverse transcription step were variable, each reverse transcription product was normalised before co-amplification. For each sample tested, reverse transcription efficiency was first evaluated by amplifying the reference gene. For the cell line study, 35 HPRT-PCR rounds were carried out with reference to the PCR amplification curve (Fig. 1). As RNA extraction efficiency from breast cancer samples was much lower than from cell lines, 40 HPRT-PCR rounds were carried out. Peak height values were compared with the reference gene PCR amplification curve determined previously (Fig. 1) and the number of coamplification PCR rounds were then adjusted for each cell line and patient sample in order to obtain PCR efficiencies where gene/HPRT ratios were reproducible.

\section{RESULTS}

\section{Internal controls as reference genes}

To assess gene expression by relative semiquantitative assay, co-amplified internal controls might be established as reference genes. Expression levels of two oestrogen independent housekeeping genes were evaluated using cDNA obtained from

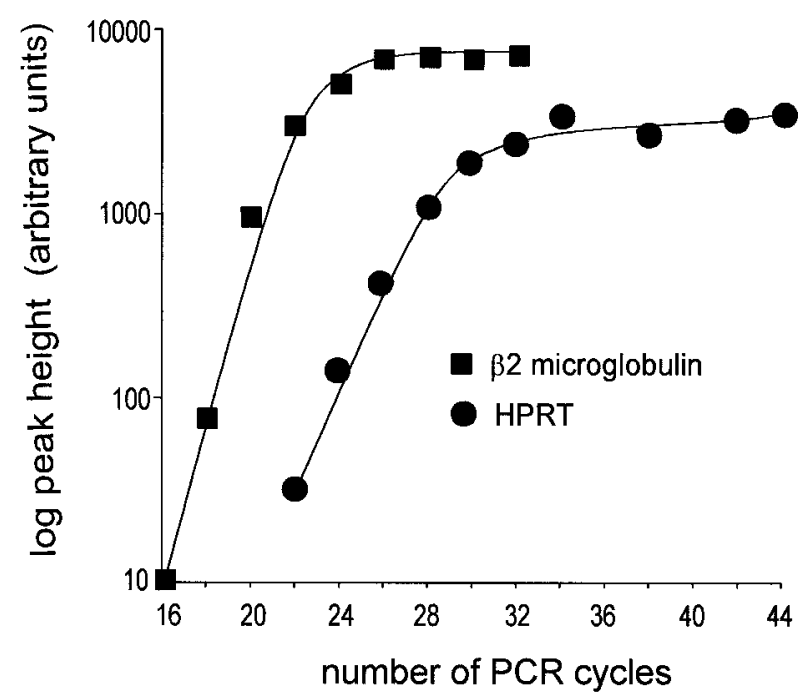

FIGURE 1. Comparison of RT-PCR amplification efficiencies of the two housekeeping genes tested, human $\beta 2$ microglobulin and human HPRT. Amplification efficiencies of cDNA obtained from Ishikawa cells ( $y$ axis) at the corresponding PCR rounds ( $x$ axis) are log peak height values obtained after runs on an Applied Biosystems 310A apparatus (Perkin Elmer).

the Ishikawa cell line: the $\beta 2 \mathrm{~m}$ gene, which is considered to be highly expressed, and the HPRT gene, which is moderately expressed in mammal cells as compared with other housekeeping genes (Foss et al. 1998). The amplification efficiencies of these genes were determined in different PCR rounds (Fig. 1). To evaluate the relative expression of each gene of interest as compared with the $\beta 2 \mathrm{~m}$ or HPRT gene, co-amplifications were performed using cDNA obtained from Ishikawa cells. PCR efficiencies were determined in different rounds when $\beta 2 \mathrm{~m}$ (Fig. 2a) or HPRT (Fig. 2b-f) were used as reference genes. As the expression level of the studied genes was low to moderate, HPRT was the most useful reference gene for this study.

\section{Repeatability and reproducibility}

Several control experiments were performed using the Ishikawa cell line RNA to validate this semi-quantitative RT-PCR technique. The 310A apparatus was evaluated by loading 10 aliquots prepared from one PCR co-amplification. Variations between peak height or peak height ratio were less than $5 \%$ (data not shown). The signal detected was found to be proportional to several cDNA dilutions added to the PCR mixture after each co-amplification with $\beta 2 \mathrm{~m}$ or HPRT (data not shown). 


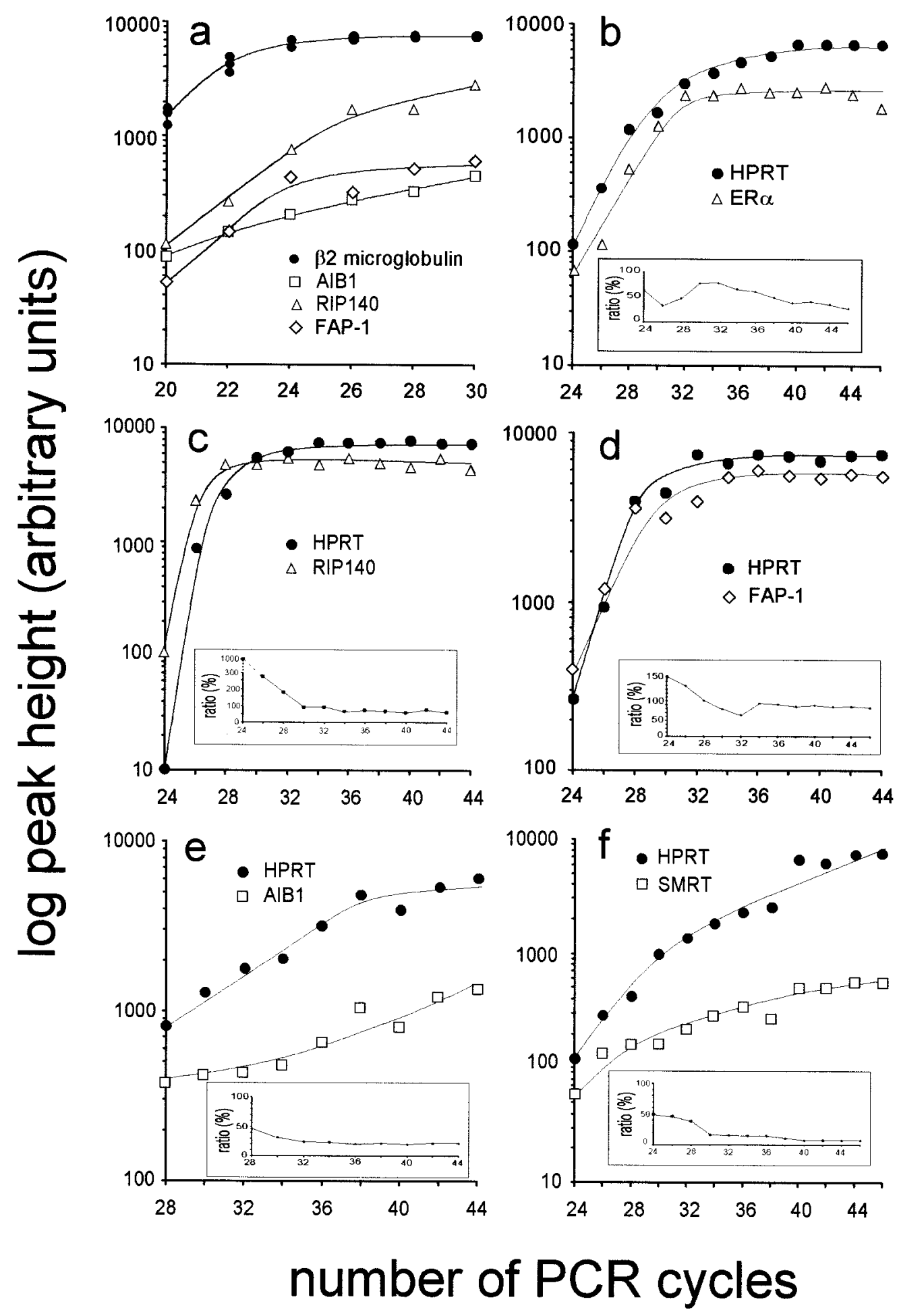

FIGURE 2. RT-PCR co-amplification efficiencies determined at different rounds. Example of one experiment performed using cDNA obtained from Ishikawa cells. The genes tested for expression level studies were co-amplified with either $\beta 2 \mathrm{~m}$ (a) or HPRT (b-f). Insets show gene/HPRT ratios during PCR rounds. 
Reproducibility of relative semi-quantification of gene expression level using HPRT as the reference gene (genes/HPRT ratio) was evaluated at different PCR rounds. As expected, PCR co-amplification ratio showed lower variations during the distal part of the exponential or log linear amplification phase. The genes/HPRT ratios were maintained during the co-amplification for a greater number of cycles than the range of log linear amplification phase (insets Fig. 2b-f). All subsequent analyses were thus performed in this range of PCR co-amplification efficiencies.

The intra-assay reproducibility of PCR coamplifications performed with the same PCR round was evaluated and showed minimal variations in the genes/HPRT ratios (5 to $11 \%$ ) (data not shown). The between-assay reproducibility of RT-PCR co-amplifications was evaluated using different RT and PCR mixes. The determination of the PCR co-amplification round was determined after each RT as described in Materials and Methods. The coefficient of variation was evaluated for each ratio after co-amplifications in 3 to 5 independent RTPCRs. The coefficient of variation was $15.5 \%$ for ER $\alpha / H P R T, \quad 13.8 \%$ for ER $\beta / H P R T, 36.9 \%$ for AIB1/HPRT, $26 \cdot 6 \%$ for RIP140/HPRT, $28 \cdot 5 \%$ for SMRT/HPRT and $20 \cdot 2 \%$ for FAP-1/HPRT.

\section{ER $\alpha$, ER $\beta$, cofactors, and FAP-1 mRNA expression levels in human breast, endometrium and ovarian cancer cell lines}

The expression pattern differences between cell lines was reproducible with two independent cell cultures (Figs 3 and 4). As expected, ER $\alpha$ was expressed at a high level $(65 \%$ to $83.9 \%)$ in ER+ cell lines (ZR75, T47D, MCF-7, Ishikawa and BG1) and was not detected or only detected at a very low level in the ER - MDA MB231 cell line. ER $\beta$ was detected at a low level $(3 \cdot 9 \%$ to $9 \cdot 3 \%)$ in all cancer cell lines tested (Fig. 3).

The AIB1 expression results (Fig. 4) were consistent with those previously published, highlighting its over-expression in MCF-7 cells $(87 \cdot 2 \%)$ and its low expression in ER - cell lines $(46 \cdot 8 \%)$ and in ZR75 (23.7\%) (Anzick et al. 1997, Thenot et al. 1999). Conversely, AIB1 expression found in BG1 cells seemed moderate but higher in T47D cells (Anzick et al. 1997, Thenot et al. 1999). AIB1 was expressed at a low level $(24.9 \%)$ in Ishikawa cells.

The RIP140 co-activator was expressed at a high level $(113 \cdot 2 \%)$ in Ishikawa cells as compared with the other cells tested in which expression levels were similar $(67 \cdot 1 \%$ to $84 \%)$ (Fig. 4$)$. The SMRT co-inhibitor was expressed at a higher level in T47D and MDA MB231 breast cancer cell lines (69.5\%

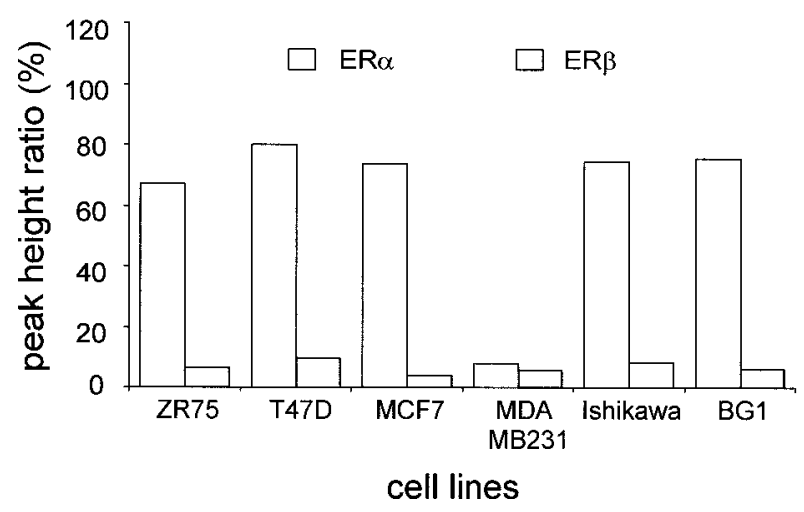

FIGURE 3. ER $\alpha$ and ER $\beta$ mRNA expression levels in human breast, endometrium and ovarian cancer cell lines. Breast cancer cell lines (ZR75, T47D, MCF-7 and MDA MB231), Ishikawa endometrial cancer cell line and BG1 ovarian cancer cell line were assessed for ER $\alpha$ and ER $\beta$ expression levels. The results are given as percentages of HPRT peak height values obtained after runs on an Applied Biosystems 310A apparatus (Perkin Elmer).

and $72 \cdot 1 \%$ respectively) than in the other cells tested $(12.7$ to $31.6 \%)$ (Fig. 4). The tyrosine phosphatase FAP-1 was expressed at a high level $(92 \cdot 2 \%)$ in T47D cells as compared with ZR75, MCF-7, MDA MB231 and Ishikawa cells $(27 \cdot 4 \%$ to $59 \cdot 2 \%)$, and was not detected in ovarian cancer cells BG1 (Fig. 4).

\section{Determination of expression level patterns in breast cancer samples (Fig. 5)}

To test the feasibility in tissue samples, pellets obtained from breast cancers were selected and expression level patterns were determined. RNA integrity and reverse transcription efficiencies were evaluated to determine the number of coamplification PCR rounds, as described in Materials and Methods. The ER results obtained at the mRNA level were correlated with those at the protein level: in the $3 \mathrm{ER} \alpha+$ samples, $\mathrm{ER} \alpha$ was highly expressed $(62 \%$ to $71 \%)$ as compared with the 3 ER $\alpha-$ samples $(3 \cdot 7 \%$ to $9 \cdot 1 \%)$. Despite the low number of tissue samples, AIB1 expression level and $\mathrm{ER} \alpha$ status seemed to be correlated as previously described (Bautista et al. 1998). Similarly, FAP-1 was mostly expressed in $\mathrm{ER} \alpha+$ samples as compared with the $\mathrm{ER} \alpha-$ (mean expression levels of the $3 \mathrm{ER} \alpha+$ samples $=29 \cdot 8 \%$ and the $3 \mathrm{ER} \alpha-$ samples $=3 \cdot 4 \%$ ). RIP140 was stably expressed in all samples tested and SMRT was not detected in ER $\alpha$-samples and either not detected or expressed at a very low level in ER $\alpha+$ samples. 


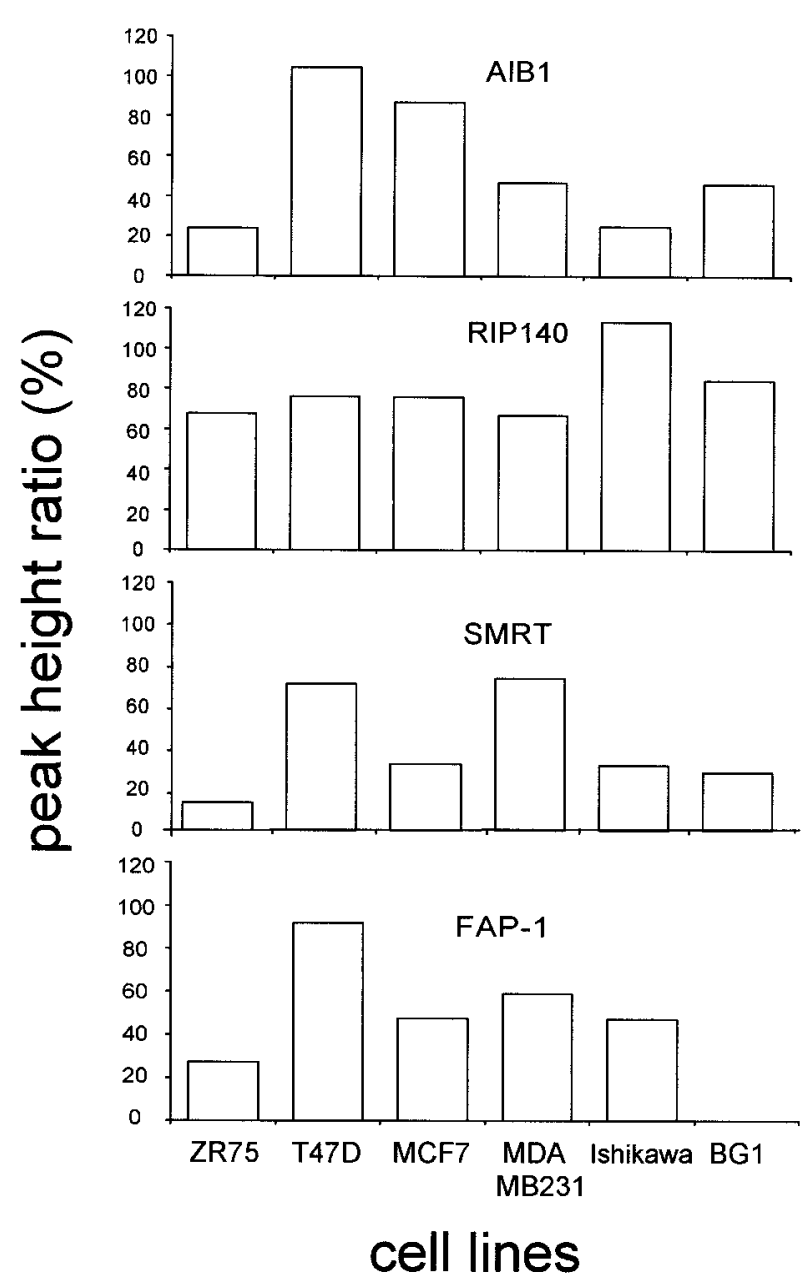

FIGURE 4. AIB1, RIP140, SMRT and FAP-1 mRNA expression levels in human breast, endometrium and ovarian cancer cell lines. Breast cancer cell lines (ZR75, T47D, MCF-7 and MDA MB231), Ishikawa endometrial cancer cell line and BG1 ovarian cancer cell line were assessed for AIB1, RIP140, SMRT and FAP-1 expression levels. The results are given as percentages of HPR'T peak height values obtained after runs on an Applied Biosystems 310A apparatus (Perkin Elmer).

\section{DISCUSSION}

Recent technological advances in the detection of protein-protein interactions, e.g. the yeast two hybrid system or the glutathione S-transferase pull-down assay, has led to the discovery of numerous new proteins involved in the oestrogen transcriptional pathway (Horwitz et al. 1996). The preponderance of some proteins as compared with others should be important for determining antioestrogen sensitivity (Takimoto et al. 1999). To test the physiological and pathological potential of these
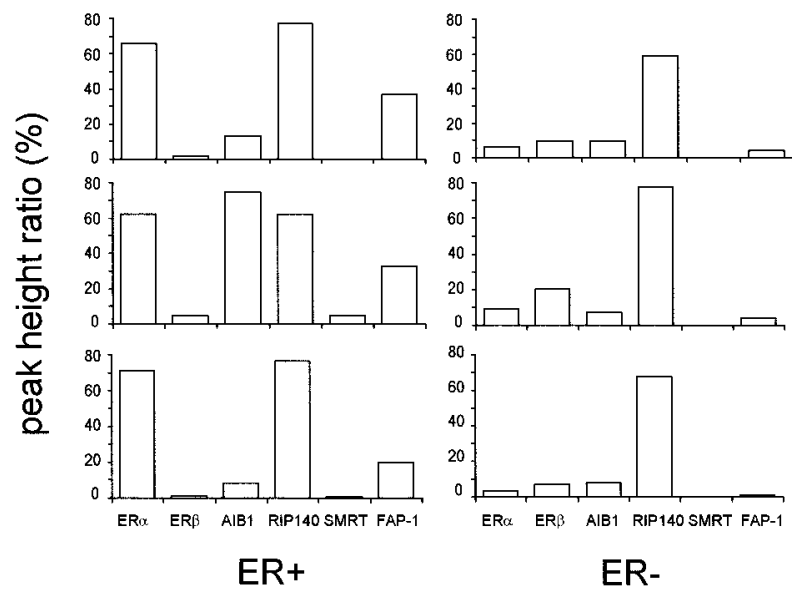

FIGURE 5. Expression patterns obtained from $3 \mathrm{ER} \alpha+$ and $3 \mathrm{ER} \alpha$ - breast cancer samples. RT-PCRs were assessed with RNAs obtained from pellets after high speed centrifugation of cytosol samples. The results are given as percentages of HPRT peak height values obtained after runs on an Applied Biosystems 310A apparatus (Perkin Elmer).

proteins, molecular techniques are useful for evaluating their expression level in oestrogen target tissues. We describe here a relative semiquantitative RT-PCR method suitable for the detection of marked variations in the expression levels of numerous genes.

A simple technique is required for screening many genes in numerous samples. To normalise the annealing temperature and reduce intra-assay variations, the oligonucleotides were designed to show a homogeneous base composition. Moreover, RT and PCR master mixes can be used for runs of at least 10 samples, including a control cell line to check between-assay reproducibility. As the efficiency of reverse transcription is variable and as a semiquantitative method must monitor the sample to sample variability of RT-PCRs, many semiquantitative RT-PCR methods are based on at least 3 different cycle-number quantitative evaluations for each sample. With this method, preliminary evaluation of relative amounts of specific cDNA were assessed by the reference gene RT-PCRs. The PCR efficiencies were then compared with the previously determined reference curve, allowing us to adjust co-amplification cycle rounds to be in the co-amplification phase where PCR ratios were reproducible.

This relative semi-quantitative RT-PCR-based method relies on co-amplification of the cDNA of interest, with a reference gene as control. Housekeeping genes such as glyceraldehyde-3-phosphate 
dehydrogenase (GAPDH) or $\beta 2 \mathrm{~m}$ are commonly used as reference genes as long as they are constitutively expressed in the cells studied and that the size of their amplification product is different from the size of the amplificate of interest. Oestradiol up-regulates GAPDH gene expression in human endometrium and cervical cancers (Kim et al. 1998, Zou \& Ing 1998). Moreover, it has been shown that tamoxifen and pregnancy up-regulate GAPDH expression in ovine endometrium (Cale et al. 1997, Robertson et al. 1998). As this method was to be applied to estimate the relative amounts of mRNAs in gynaecological tissues (breast, endometrium and ovaries), GAPDH was not the most appropriate reference gene. The ratio of amplified products must reflect the initial ratio of the two mRNAs in the starting material. However, the target mRNA is usually present in much lower copy number than the housekeeping gene. In this study, the $\beta 2 \mathrm{~m}$ amplification yield was too high with respect to the products of interest, and plateaued before the target product could be visualised. Rather than decrease the concentration of $\beta 2 \mathrm{~m}$ specific oligonucleotides in PCR mixes that would rapidly reach a plateau phase or adding $\beta 2 \mathrm{~m}$ specific oligonucleotides after a few amplification cycles, the least expressed HPRT housekeeping gene was chosen as the reference gene. Beta $2 \mathrm{~m}$ can be used as the reference gene for semi-quantitative studies of highly expressed genes. Competitive RT-PCR, using a specific mutated mRNA as internal control for each gene studied, allows an accurate quantification of the starting amounts of mRNA. In this relative semi-quantitative technique, differences between the expression levels and the PCR efficiencies of the genes studied as compared with HPRT showed that the amplification efficiencies might not always be in the exponential phase at the same time. A range of PCR co-amplification efficiencies where the gene/HPRT ratio showed low variation was determined and was found during the late exponential phase as well as during the beginning of the linear phase. On the other hand, generation of specific internal controls by deletion of a few bases for accurate evaluation of reverse transcription efficiency and quantitative PCRs was not suitable for a rapid screening of numerous genes. Real-time detection for truly quantitative PCR using TaqMan (Perkin Elmer, Courtaboeuf, France) technology is based upon the interdependency between the number of PCR cycles that are required to detect a template and the number of template molecules initially present in a sample to quantify unknown samples. Template concentration is determined at the PCR cycle when the amplification signal enters the log linear region.
This relative semi-quantitative RT-PCR allowed a between samples comparison of genes expression level and not the determination of template molecules initially present. Therefore, all subsequent amplifications were performed in the same range of PCR efficiency.

Better results can be obtained when the two co-amplified fragments do not differ by more than $400 \mathrm{bp}$ in length (Santagati et al. 1997), and to avoid marked differences in PCR efficiencies fragments from 163 to $386 \mathrm{bp}$ were chosen for co-amplifications. Using two different fluorophore tags, and as the $310 \mathrm{~A}$ can differentiate fragments varying by $2 \mathrm{bp}$, amplified fragments of similar lengths could be distinguished easily e.g. RIP140/ HPRT.

The results obtained in these cell lines were largely in agreement with those previously obtained using Northern blot (Anzick et al. 1997, Thenot et al. 1999). However, in our hands the ER+ breast cancer cell line, T47D, showed high AIB1 mRNA expression, contrasting with the low signal previously obtained by Northern blot (Anzick et al. 1997, Thenot et al. 1999). In breast cancer samples, ER results obtained at the mRNA level were consistent with those at the protein level and, even though the number of samples tested was low, the correlation between the AIB1 expression level and $\mathrm{ER} \alpha$ status seemed to be confirmed (Bautista et al. 1998).

Semi-quantitative RT-PCR provides a rapid and reliable way of quantitating the amounts of a given mRNA present in small quantity. Due to the resolution limit of ethidium bromide staining detection, an Applied Biosystems 310A apparatus (Perkin Elmer) was used and permitted the detection of fragments that did not appear after runs on $2 \%$ agarose or $5 \%$ acrylamide gels. Moreover, this method was easily reproducible and sensitive for detecting low mRNA expression. Despite the low expression of some genes (AIB1 and SMRT in Ishikawa cells), marked variations could be detected. This technique might be useful for detecting wide variations in oestrogen-related gene expression in gynaecological pathologies and pharmacological studies, and might lead to further experiments at the protein level for developing new biological markers.

\section{ACKNOWLEDGEMENTS}

We thank S Thenot for providing the cell cultures. This work was supported by the Institut National de la Santé et de la Recherche Médicale, the University of Montpellier I, the Centre Hospitalier 
Universitaire de Montpellier, the Ligue Contre le Cancer and the Fondation pour la Recherche Médicale.

\section{REFERENCES}

Anzick S, Kononen J, Walker RL, Azorsa DO, Tanner MM, Guan XY, Sauter G, Kallioniemi OP, Trent JM \& Meltzer PS 1997 AIB1, a steroid receptor coactivator amplified in breast and ovarian cancer. Science 277 965-968.

Bautista S, Vallès H, Walker RL, Anzick S, Zellinger R, Meltzer P \& Theillet C 1998 In breast cancer, amplification of the steroid receptor coactivator gene AIB1 is correlated with oestrogen and progesterone receptor positivity. Clinical Cancer Research 4 2925-2929.

Cale JM, Millican DS, Itoh H, Magness RR \& Bird IM 1997 Pregnancy induces an increase in the expression of glyceraldehyde-3-phosphate dehydrogenase in uterine artery endothelial cells. Fournal of the Society of Gynecologic Investigation 4 284-292.

Cavaillès V, Dauvois S, L'Horset F, Lopez G, Hoare S, Kushner PJ \& Parker MG 1995 Nuclear factor RIP140 modulates transcriptional activation by the estrogen receptor. EMBO Fournal 14 3741-3751.

Chen JD \& Evans RM 1995 A transcriptional co-repressor that interacts with nuclear hormone receptors. Nature $\mathbf{3 7 7}$ 454-457.

Foss DL, Baarsh MJ \& Murtaugh MP 1998 Regulation of hypoxanthine phosphoriboyltransferase, glyceraldehyde-3phosphate dehydrogenase and beta-actin mRNA expression in porcine immune cells and tissues. Animal Biotechnology 9 $67-78$.

Freiss G, Puech C \& Vignon F 1998 Extinction of the insulinlike growth factor-I mitogenic signaling by antiestrogenstimulated fas-associated protein tyrosine phosphatase-1 in human breast cancer cells. Molecular Endocrinology 12 $568-579$.

Horwitz KB, Jackson TA, Bain DL, Richer JK, Takimoto GS \& Tung L 1996 Nuclear receptor coactivators and corepressors. Molecular Endocrinology 10 1167-1177.

Jolly DJ, Okayama H, Berg P, Esty AC, Filpula D, Bohlen P, Johnson GG, Shively JE, Hunkapillar T \& Friedmann T. 1983 Isolation and characterization of a full-length expressible cDNA for human hypoxanthine phosphoribosyl transferase. Proceedings of the National Academy of Sciences of the USA $80477-481$.
Kim JW, Kim SJ, Han SM, Paik SY, Hur SY, Kim YW, Lee JM \& Namkoong SE 1998 Increased glyceraldehyde-3phosphate dehydrogenase gene expression in human cervical cancers. Gynecologic Oncology 71 266-269.

Maekawa K, Imagawa N, Nagamatsu M \& Harada S 1994 Molecular cloning of a novel protein-tyrosine phosphatase containing a membrane binding domain and GLGF repeats. FEBS Letters 337 200-206.

Pujol P, Rey JM, Nirde P, Roger P, Gastaldi M, Laffargue F, Rochefort H \& Maudelonde T 1998 Differential expression of the oestrogen receptor- $\alpha$ and $-\beta$ messenger RNAs as a potential marker of ovarian carcinogenesis. Cancer Research 58 5367-5373.

Robertson JA, Bhattacharyya S \& Ing NH 1998 Tamoxifen up-regulates oestrogen receptor-alpha, c-fos and glyceraldehyde-3-phosphate dehydrogenase mRNAs in ovine endometrium. Fournal of Steroid Biochemistry and Molecular Biology 67 285-292.

Santagati S, Garnier M, Carlo P, Violani E, Picotti GB \& Maggi A 1997 Quantitation of low abundance mRNAs in glial cells using different polymerase chain reaction (PCR)based methods. Brain Research: Brain Research Protocols 1 217-223.

Smith CL, Nawaz Z \& O’Malley BW 1997 Coactivator and corepressor regulation of the agonist/antagonist activity of the mixed antiestrogen, 4-hydroxytamoxifen. Molecular Endocrinology 11 657-666.

Suggs SV, Wallace RB, Hirose T, Kawashima EH \& Itakura K 1981 Use of synthetic oligonucleotides as hybridization probes: isolation of cloned cDNA sequences for human beta 2-microglobulin. Proceedings of the National Academy of Sciences of the USA 78 6613-6617.

Takimoto GS, Graham JD, Jackson TA, Tung L, Powell RL, Horwitz LD \& Horwitz KB 1999 Tamoxifen resistant breast cancer: coregulators determine the direction of transcription by antagonist-occupied steroid receptors. Fournal of Steroid Biochemistry and Molecular Biology 69 45-50.

Thenot S, Charpin M, Bonnet S \& Cavaillès V 1999 Estrogen receptor cofactor expression in breast and endometrial human cancer cells. Molecular and Cellular Endocrinology 156 85-93.

Zou K \& Ing NH 1998 Oestradiol up-regulates oestrogen receptor, cyclophilin, and glyceraldehyde phosphate dehydrogenase mRNA concentrations in endometrium, but down-regulates them in liver. Fournal of Steroid Biochemistry and Molecular Biology 64 231-237.

REVISED MANUSCRIPT RECEIVED 30 December 1999 